\title{
Investigation of erosion behavior of 304 stainless steel under solid-liquid jet flow impinging at $30^{\circ}$
}

\author{
Yan-Lin Zhao ${ }^{1}$ Chun-Yan Tang ${ }^{1}$. Jun Yao ${ }^{1} \cdot$ Zi-Hua Zeng $^{2} \cdot$ Shi-Gang Dong ${ }^{2}$
}

Received: 7 February 2019 / Published online: 29 June 2020

(c) The Author(s) 2020

\begin{abstract}
This work carried out liquid-solid two-phase jet experiments and simulations to study the erosion behavior of 304 stainless steel at $30^{\circ}$ impingement. The single-phase impinging jet was simulated using dense grid by one-way coupling of solid phase due to its dilute distribution. The simulation results agreed well with experiments. It was found that after impinging particle attrition occurred and particles became round with decreasing length-ratio and particle breakage occurred along the "long" direction. Both experiment and simulations found that the erosion generated on the sample could be divided into three regions that were nominated as stagnant region, cutting transition region and wall jet region. Most particle-wall impacts were found to occur in the cutting transition region and the wall jet region. In the cutting transition region, holes and lip-shaped hogbacks were generated in the same direction as the flow imping. In the wall jet region, furrows and grooves were generated. The averaged grooves depth tended to become constant with the progress of impinging and reach the steady state of erosion in the end. In addition, it was found that impinging effect increased erosion and anti-wear rate.
\end{abstract}

Edited by Xiu-Qiu Peng

Yan-Lin Zhao

ylzhao@cup.edu.cn

1 Beijing Key Laboratory of Process Fluid Filtration and Separation, College of Mechanical and Transportation Engineering, China University of Petroleum-Beijing, Beijing 102249, People's Republic of China

2 College of Energy, Xiamen University, Xiamen 361005, People's Republic of China 


\section{Graphic abstract}
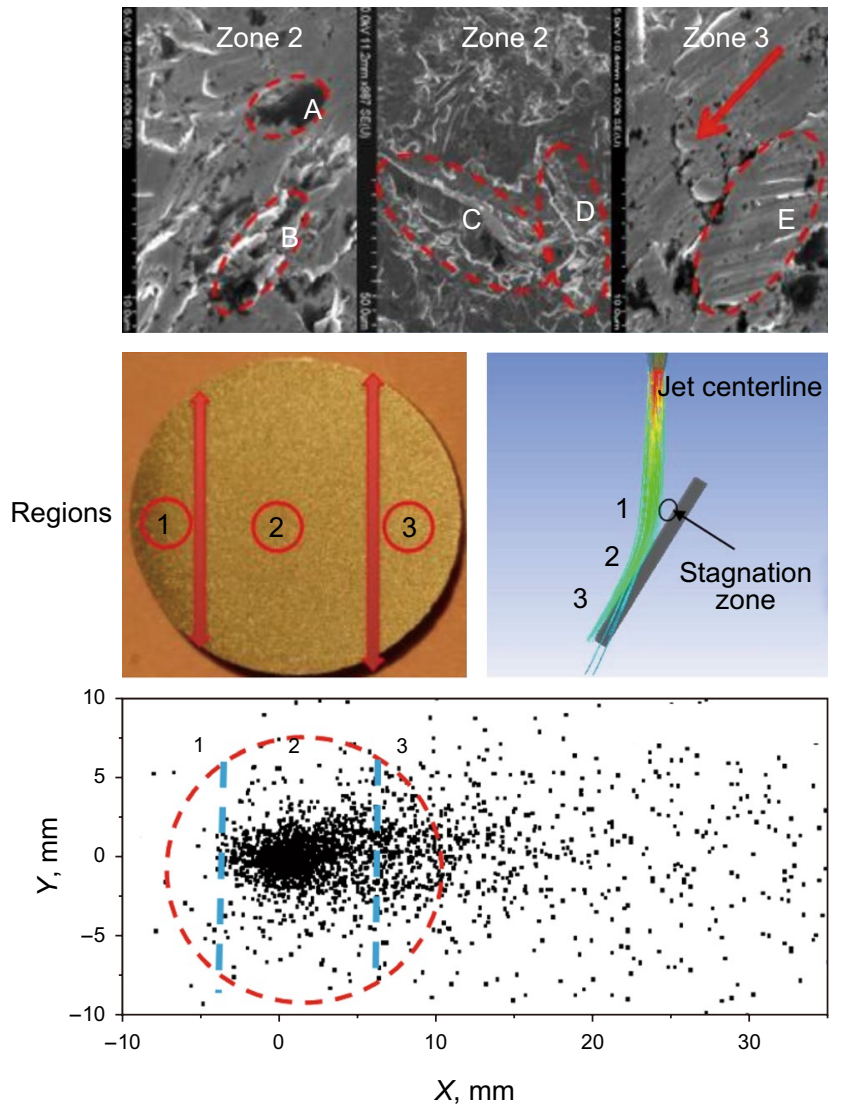

Keywords Solid-liquid flow · Impinging jet · Erosion · Experiment · Numerical simulation

\section{List of symbols}

A Empirical constant determined by wall material, dimensionless

$B_{\mathrm{H}} \quad$ Material Brinell hardness, $\mathrm{N} \mathrm{mm}^{-2}$

$C \quad$ Erosion constant, dimensionless

$C_{\mathrm{D}} \quad$ Drag coefficient, dimensionless

$D$ Particle diameter, $\mathrm{mm}$

$E_{\mathrm{R}} \quad$ Material erosion rate, $\mathrm{kg} \mathrm{m}^{2} \mathrm{~s}^{-1}$

EV The volume loss of target material, $\mathrm{m}^{3}$

$f \quad$ Body force, $N$

$F \quad$ Drag force acted on a particle, $N$

$F_{\text {s }} \quad$ Particle shape coefficient, dimensionless

$k \quad$ Erosion volume constant, dimensionless

$m \quad$ Particle mass, kg

$n \quad$ Particle-wall impact speed constant, dimensionless

$p \quad$ Flow stress, $\mathrm{N} \mathrm{m}^{-2}$

$R e_{\mathrm{p}} \quad$ Particle Reynolds number, dimensionless

$t$ Time, s

$u \quad$ Time-averaged velocity, $\mathrm{m} \mathrm{s}^{-1}$

$u^{\prime} \quad$ Fluctuation velocity, $\mathrm{m} \mathrm{s}^{-1}$
$V \quad$ Particle impact velocity, $\mathrm{m} \mathrm{s}^{-1}$

$x \quad X$-direction at spatial coordinate, dimensionless

\section{Greek symbols}

$v \quad$ Kinematic viscosity, $\mathrm{m}^{2} \mathrm{~s}^{-1}$

$\beta \quad$ Particle-wall impact angle, radians

$\rho \quad$ Density, $\mathrm{kg} \mathrm{m}^{-3}$

$\tau \quad$ Stress, $\mathrm{N} \mathrm{m}^{-2}$

\section{Subscripts}

$f \quad$ Continuous phase

$i \quad$ Spatial orientation

$n \quad$ Velocity components normal to wall

$t \quad$ Velocity components tangential to wall

$p \quad$ Particle phase

1 Before particle-wall impact

2 After particle-wall impact 


\section{Introduction}

Austenitic stainless steels are widely used in industrial multiphase flow systems, mainly in petroleum engineering, petrochemical engineering, food transportation, nuclear power plants and so on. Erosion behavior has caused a series of problems in whole multiphase flow (Yin et al. 2018) operating systems and became one of the main material damages occurred in pipe line systems (Fan et al. 2001). Particle-wall impact usually causes particle attrition and wall erosion with mass loss. After long-term working it leads to pipe broken, equipment failure and other major engineering problems (Han et al. 2018). In order to improve the abrasion resistance of equipment in solid-liquid two-phase flows, researchers have conducted a lot of work and developed erosion models and wear mechanisms. Nguyen et al. (2014a, b) investigated the working mechanisms of slurry erosion of stainless steel using erosion test rig, where the multiphase flows of alumina sand and water were utilized. They found that the erosion rate and surface roughness increased with sand impact velocity, where microstructural presence revealed two different erosion mechanisms. Plastic deformation mechanism dominated at high impact angles and plowing/ cutting mechanism dominated at low impact angles. Telfer et al. (2012) investigated the effect of particle material and target material on the erosion mechanism and they reported that the erosion rate increased with particle size in the passive region while the wastage regime remained relatively unchanged. Rajahram et al. (2011) applied a modified slurry pot erosion tester to perform in situ electrochemical measurement of solid particle impingement. They investigated the effect of flow velocity, sand size and sand concentration on the erosion of a passive metal (UNS S31603). It is found that the highest corrosion current occurred for medium-sized particle and followed by coarse particle and fine particle. The current of erosion-corrosion increased with particle velocity due to high kinetic energy of particles. As sand concentration increased from 1 to $5 \mathrm{wt} \%$, noise increased with the frequency of particle-wall impacting and oxide film removing. On the other hand, with the progress of modeling technologies, more and more researchers tended to simulate the erosion and corrosion occurred in multiphase flows. Ben-Ami et al. (2016) developed a model to predict the maximum erosion including impinging angle, hardness and fracture toughness. The model indicated that the ratio of fracture toughness to hardness of the target material dominated the erosion. Akama and Kimata (2020) set up a numerical model to simulate crack propagation and wear competition. Qi et al. (2017) applied CFD (Computational Fluid Dynamics) method coupled with erosion model to study the effect of ultrasonic vibration on glass erosion caused by particle impact occurred in an abrasive slurry jet machining process. The erosion increased with particle impact as well as ultrasonic vibration so that the abrasive slurry jet machining area increased with it. Such results were used to improve the abrasive slurry jet micro-machining efficiency and quality. Agrawal et al. (2019) added turbulence dispersion to the particle tracking algorithm and proposed that random particle tracking parameters can be used to predict the erosion. Jin et al. (2012) applied point-particle Eulerian-Lagrangian method in combined with direct numerical simulation (DNS) method (for flow phase) to investigate particle-laden flows in $10 \times 11 \mathrm{stag}$ gered stainless steel tube banks. Particle-wall collision and tube erosion were well predicted. Due to particle-wall impact leading to surface erosion, the coarse wall caused some new problems. Luo et al. (2007) developed a modified immersed boundary method to fully-resolved direct numerical simulation of fluid-particle interactions, which was able to achieve reliable accuracy for considering the interactions between fluid and particle (Alade et al. 2019). A physical nonlinear-weighted average strategy based on the boundary layer theory was then proposed, where the effect of direct force was considered and the flow velocity near particle boundary was well predicted. It could be believed that such progress of modeling methodologies would largely improve the prediction of erosion and corrosion occurred in multiphase flows.

To prevent material from erosion, Fan et al. (2001) showed that adding ribs to elbow could obviously reduce the erosion rate. The effects of particle size (Telfer et al. 2012; Yao et al. 2015), impact angle (Nguyen et al. 2014b; Ben-Ami et al. 2016; Mohammadi and Luo 2010; Zhang et al. 2009), impact angle (Nguyen et al. 2014b; Ben-Ami et al. 2016; Zhang et al. 2009), water chemistry (Aribo et al. 2013) and particle concentration (Luo et al. 2007) on material erosion were widely investigated. In addition, the effect of carbide against the erosion of plastic material was studied (Lopez et al. 2005). It was found that the resistance to erosion decreased carbon concentration, however, as the carbide concentration was higher than $80 \%$ the erosion resistance increased with carbon concentration. It was known that the working mechanism of erosion varied with material. For example, for a plastic material, the micro-cutting theory adapted to small impact angle (Finnie et al. 1992) while the deformation wear theory adapted to large impact angle (Bitter 1963). The theories of forging and extruding using single particle tracking method for brittle materials were developed by Levy et al. (Levy 1988). The microscopic wear mechanism (Finnie et al. 1992) was used to investigate particle trajectories in the case of large impact angle.

Particle-wall impact angle is known as one of important factors that affect erosion in multiphase flow systems. It 
has been confirmed by many investigations. For example (Finnie 1960; Tilly and Sage 1970), it was found that for ductile target, the erosion increased with impact angle first and then decreased and the maximum erosion occurred at $20^{\circ}$ and $30^{\circ}$ of particle-wall impact angle. However, for brittle material such as glass, the erosion rate increased with impact angle and reached the maximum as the particle impact angle was at $90^{\circ}$. The same result was further confirmed by Pool et al. (1986). Wellman and Allen (1995) studied the ceramics erosion at several angles and found that it was sensitive to particle impact angle particularly in the range of $45^{\circ}$ to $60^{\circ}$. He argued that such phenomenon could be ascribed to particle-wall impact velocity and particle shape. At a high impact angle as $60^{\circ}$, the material removed from the formation of lateral fracture and chips removed from the surface while at low impact angle as $30^{\circ}$, most erosion appeared to be plastic in the formation of lateral cracking. Samimi et al. (2004) investigated the effect of particle-wall impact angle on the agglomeration of impact damage and found that the extent of breakage increased with decreasing the impact angle as particle impact velocity ranged from 15 to $35 \mathrm{~m} \mathrm{~s}^{-1}$. As the agglomeration break occurred in the chipping region, i.e., by surface damage at low impact velocities (less than $15 \mathrm{~m} \mathrm{~s}^{-1}$ ), it was the normal component of the impact velocity that determined the breakage, which was independent of the impact angle. However, at a high impact velocity it was the tangential component of the impact velocity that determined the fragmentation. Yi et al. (2019) studied the critical flow velocity (CFV) in different local eroded regions and found the relationship between exposed area of a sample and CFV behavior. Yildizli et al. (2006) studied the erosion of nodular cast iron (NCI) and gray cast iron (GCI) occurred at intermediate and normal impact angle and found that considerable weight loss varied with the impact angle, where the highest erosion rate occurred at impact angle $30^{\circ}$, the intermediate rate at $60^{\circ}$ and the lowest rate at normal impact angle. In addition, the erosion rate of NCI was lower than that of GCI at all impact angles. In all cases, the erosion occurred most in a ductile process. At an oblique impact angle $\left(30^{\circ}\right.$ or $\left.60^{\circ}\right)$, hard erodent was generated by plastic flow in relatively softer surface of NCI and removed by micro-cutting and micro-plowing. At a normal impact angle, material loss from NCI surface occurred by gauging. Al-Bukhaiti et al. (2007) investigated the effect of impingement angle on the slurry erosion of 1017 steel and high-chromium white cast iron in three regions. In the region $\theta \leq 15^{\circ}$ the shallow plowing and particle rolling dominated the erosion, while in the region $15^{\circ}<\theta<75^{\circ}$, micro-cutting and deep plowing were found to be dominant and as $\theta \geq 75^{\circ}$ indentation and extrusion were found to be dominant. For high-Cr white cast iron, at low impingement angles $\left(\leq 45^{\circ}\right)$ plastic deformation of the ductile matrix dominated the erosion while at high impingement angles $\left(\geq 45^{\circ}\right)$ gross fracture and cracking of the carbides were found to be dominant. Nguyen et al. (2014b) studied the effect of impact angle on stainless steel erosion at high velocities and found that the maximum erosion occurred at $40^{\circ}$. Investigation of the surface microstructure confirmed that the erosion depended on the impact angle. The erosion from microplowing to indentation caused plastic deformation from low to high impact angle. The tribo-corrosive wear of AISI 316 stainless steel under high-speed jet impingement by liquid-solid flows was investigated by Zhao et al. (2015). It was found that the weight-loss of the metal specimens increased with decreasing impact angle $\left(20^{\circ}-75^{\circ}\right)$, which mostly attributed to the combined effect of two types of erosion occurred simultaneously, repeated deformation due to normal stress and cutting wear due to shear stress. Yao et al. (2015) applied experimental method to investigate the erosion of stainless steel 304, 316 by two-phase jet impingement and found that the maximum erosion rate occurred in 12-15 $\mathrm{h}$ test and the erosion mechanism for different impact angle was obviously different. In addition, an erosion model developed by Ben-Ami et al. (2016) could predict the maximum erosion well based on impingement angle as well as physical properties such as hardness $(\mathrm{H})$ and fracture toughness $(\mathrm{R})$. The ratio of the target material fracture toughness to the hardness might dominate the erosion mechanism and the angle that the maximum erosion occurred. Furthermore, particle-wall impact angle did affect erosion-corrosion interaction. Stack et al. (1999) investigated the effect of the impact angle on the boundaries of the erosion-corrosion. Burstein and Sasaki (2000) studied it on the corrosion-erosion of AISI 304L stainless steel and found that the maximum erosion and corrosion-erosion rates in chloride solution both occurred at $40^{\circ}$ and $50^{\circ}$. Abedini and Ghasemi (2014) and Khayatan et al. (2017) investigated the erosion and erosion-corrosion behaviors of Al-brass alloy by using slurry impingement rig at $6 \mathrm{~m} \mathrm{~s}^{-1}$ and the impingement angle ranged in $20^{\circ}-90^{\circ}$, which found that the maximum erosion and erosion-corrosion rates occurred at $40^{\circ}$.

In short, the erosion occurred at low particle-wall impact angles and associated microscopic wear mechanisms have not been fully understood. Particularly, the working mechanism of long-term impingement particularly at low impact angle has little been studied. In this work, a sand-liquid two-phase impingement jet was set at $30^{\circ}$ and the erosion behavior of 304 stainless steel was investigated using both experimental test and numerical simulation. The effects of particle size, particle-wall impact regions, impact frequency were considered. Material phase of impacted area and surface modification were investigated and then micro-cutting theory was developed. 


\section{Methodology}

\subsection{Experiment}

\subsubsection{Materials and specimens}

In this work, AISI 304 stainless steels were impinged by sand-liquid two-phase flow. The chemical composition of AISI 304 stainless steel is shown in Table 1. The diameter of the stainless steel sample tested was $16 \mathrm{~mm}$ and the thickness was $2 \mathrm{~mm}$. Before each test, specimens were polished by SIC paper with the sequence of the sand size of 180 grit, 400 grit, 600 grit, 800 grit, 1200 grit, up to 2000 grit. After that, all metal specimens were cleaned by ethanol in KQ5200DE numerical control ultrasonic cleaner and rinsed by deionized water. Temperature pretreatment was used to remove the solution left on surface. Before each test, a specimen was weighed three times and the averaged value was considered as the original weight. For this experiment, the solid-liquid flow was used and the mass fraction of silica sand was $0.5 \%$.

\subsubsection{Experimental setup}

The experiment setup used in this work is shown in Fig. 1. It was a two-phase high-speed impinging jet loop. The power

Table 1 The chemical composition of 304 SS

\begin{tabular}{ll}
\hline Composition & wt, $\%$ \\
\hline $\mathrm{C}$ & 0.024 \\
$\mathrm{Si}$ & 0.550 \\
$\mathrm{Mn}$ & 1.800 \\
$\mathrm{P}$ & 0.030 \\
$\mathrm{~S}$ & 0.001 \\
$\mathrm{~N}$ & 0.049 \\
$\mathrm{Cr}$ & 18.200 \\
$\mathrm{Ni}$ & 8.200 \\
$\mathrm{Fe}$ & $\mathrm{Bal}$. \\
\hline
\end{tabular}

source used in the system was a $1.5 \mathrm{~kW}$ water pump, which was able to pump solid-liquid two-phase flow from a water storage tank through a pipeline with a $13 \mathrm{~mm}$-diameter nozzle to impinge samples. In the experiments, the pipeline was set to be full of liquid so that the flow was fully developed and the nozzle outlet flow velocity was equal to $10.5 \mathrm{~m} \mathrm{~s}^{-1}$. The nozzle was fastened by metal framework to make sure being stable in the process of impinging and avoid impinging shock (shown in Fig. 1b). In addition, the tested sample was fixed using a rotatable holder, which was inserted at a hole (shown in Fig. 1a). Under the effect of impinging jet, the sample was stick to the holder tightly rather than excite from the hole. The impinging angle between jet and specimen could be adjusted by the rotatable holder. In this study, the jet impinging angle was set at $30^{\circ}$. High-speed camera (Photron, high-speed digital video camera FASTCAM Mini UX50, Japan) was used to observe and record the flow information of liquid-solid impinging jet (Fig. 1b). This camera can take 2000 frames per second (fps) at full resolution and its maximum speed can reach $160 \mathrm{Kfps}$. The Mono/Color resolution is 12 bits/36 bits and C-MOS image sensor has $1280 \times 1024$ pixels. The velocity of the liquid-solid impinging jet was measured at $10.5 \mathrm{~m} \mathrm{~s}^{-1}$.

\subsubsection{Experimental conditions}

In this work, experimental measurements might be affected by some factors, such as liquid temperature, the time-length of the interval between experiments, liquid $\mathrm{PH}$ and so on. To remove these effects, some countermeasures were used. For example, before each test, the system would turn on in advance to increase the liquid temperature to a constant level $\left(45^{\circ}\right)$. During the impinging process, the liquid temperature was at the same level due to motor running. All tested samples were weighted after each test and then continuously tested. The effect of the interval between two tests on the final result could be ignored because such effect caused by a pause was very little (Yao et al. 2015). In addition, the liquid used was deionized water and neither chemistry solution nor chemical reaction was involved so that the $\mathrm{PH}$ effect on
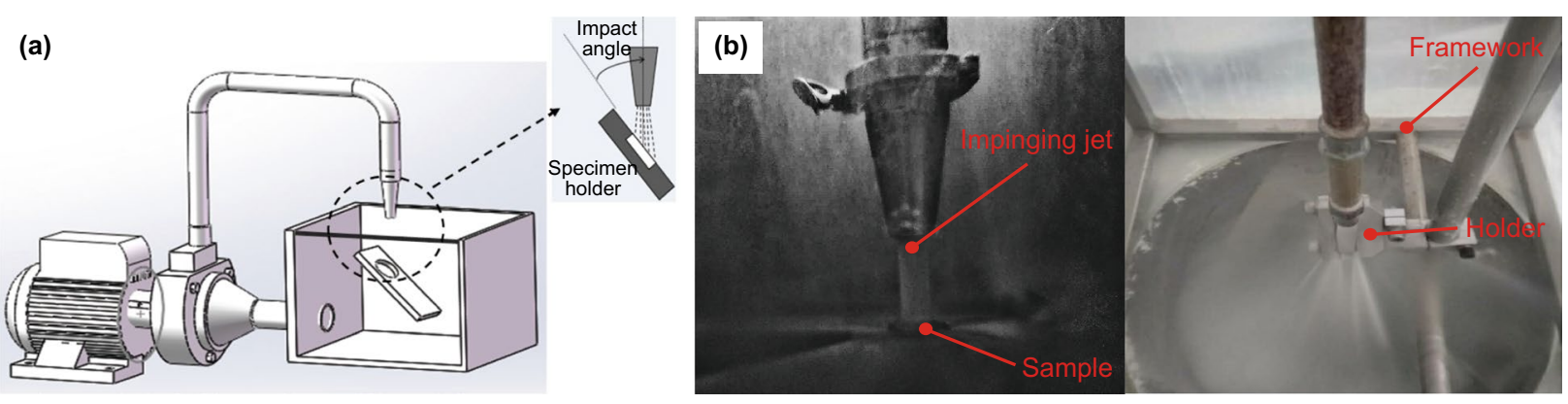

Fig. 1 a Schematic diagram of the experimental set up; b impinging process taken by the high-speed camera: left: at side; right: at top 
experimental measurement could be ignored. After each test, the tested sample was timely cleaned, weighted and vacuum sealed so that the oxide film would not be generated.

\subsection{Simulation method}

\subsubsection{Flow field}

In this work, Reynolds stress model (Fan et al.2001) was used to simulate the flow field, which established differential models of ripple stress in the Reynolds equation. In the Cartesian coordinate system, the continuous equation of incompressible flow and instantaneous momentum could be written as:

$\frac{\partial u_{j}}{\partial x_{j}}=0$

$\frac{\partial u_{j}}{\partial t}+u_{j} \frac{\partial u_{i}}{\partial x_{j}}=f_{i}-\frac{1}{\rho} \frac{\partial p}{\partial x_{i}}+\frac{1}{\rho} \frac{\partial \tau_{i j}}{\partial x_{j}}$

The Reynolds stress model could be presented as following:
The simulation area referred to the experiment setup is shown in Fig. 2. Related simulations were carried out to calculate erosion occurred, where nozzle size, tested sample surface and tank floor were considered. The boundary conditions were set as following. The nozzle inlet was set as velocity inlet. The walls of the nozzle, tested sample and tank bottom were all set as nonslip solid boundary. The upper boundary and other four boundaries were set as pressure outlet boundaries as shown in Fig. 2. Discrete term boundary was reflected. The mesh was drawn as hybrid polyhedral and encrypted near the impact wall with a number of 1.85 million. The time step was constant with the maximum of the Courant number lying between 0.1 and 0.3 . The indoors code used was developed from the previous work (Fan et al. 2001) and has been verified by many previous numerical studies for a wide range of flows, such as wake flow (Yao et al. 2012), pipe flow (Yao et al. 2020) and duct flow (Zhao et al. 2018). The turbulent flow model used was the RNG- $k-\varepsilon$ model and the wall processing function was based on the wall processing method. The first-order upwind scheme was applied to the convective term and diffusion term. The accuracy of the residuals used was $10^{-3}$.

$$
\begin{aligned}
& \frac{\partial \overline{u_{i}^{\prime} u_{j}^{\prime}}}{\partial t}+\overline{u_{k}} \frac{\overline{u_{i}^{\prime} u_{j}^{\prime}}}{\partial x_{k}}=\frac{\partial}{\partial x_{k}}\left[\overline{-\frac{\rho^{\prime}}{\rho}\left(u_{i}^{\prime} \delta_{j k}+u_{j}^{\prime} \delta_{i k}\right)}-\overline{u_{i}^{\prime} u_{j}^{\prime} u_{k}^{\prime}}\right]+\frac{\partial}{\partial x_{k}}\left(\overline{v \overline{u_{i}^{\prime} \partial u_{j}^{\prime}}} \frac{\overline{\partial x_{k}}}{)}\right) \\
& -\left(\overline{u_{i}^{\prime} u_{k}^{\prime}} \frac{\partial \overline{u_{j}}}{\partial x_{k}}+\overline{u_{j}^{\prime} u_{k}^{\prime}} \frac{\partial \overline{u_{i}^{\prime}}}{\partial x_{k}}\right)+\left(\overline{f_{i}^{\prime} u_{j}^{\prime}}+\overline{f_{j}^{\prime} u_{i}^{\prime}}\right) \\
& +\overline{\frac{\rho^{\prime}}{\rho}\left(\frac{\partial u_{i}^{\prime}}{\partial x_{j}}+\frac{\partial u_{j}^{\prime}}{\partial x_{i}}\right)}-2 v \frac{\overline{u_{i}^{\prime} u_{j}^{\prime}}}{\partial x_{k} \partial x_{k}}-2 \Omega_{k}\left(\overline{u_{j}^{\prime} u_{m}^{\prime}} \varepsilon_{i k m}+\overline{u_{i}^{\prime} u_{m}^{\prime}} \varepsilon_{i k m}\right) \text {. }
\end{aligned}
$$

(a)

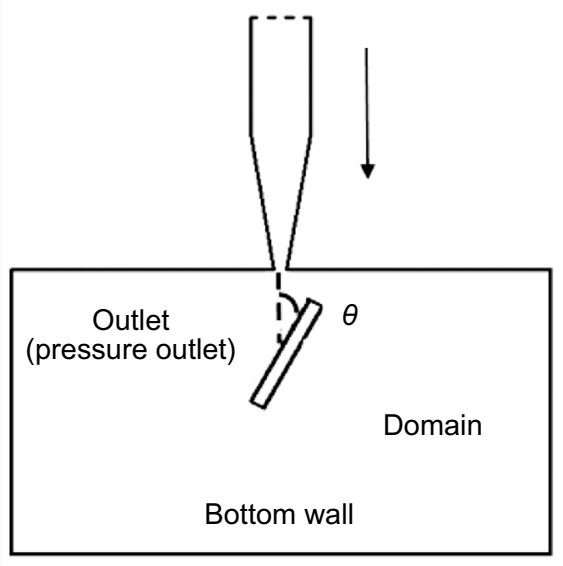

(b)

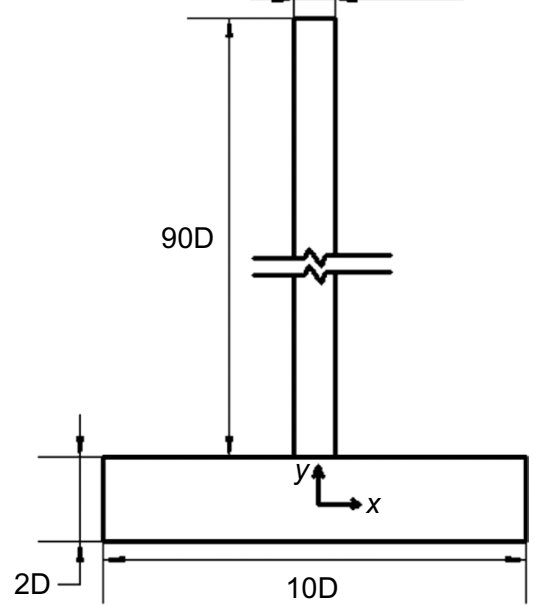

Fig. 2 a Calculation area and boundary conditions; b computational domain and coordinate system 


\subsubsection{Discrete phase control equation}

The particle trajectory was solved by Lagrangian method (Fan et al. 2001). The particle fraction in the flow was set the same as the experimental level $0.5 \%$. Due to low particle concentration and high-density difference between flow and particle, some additional forces caused by flow resistance, mass force, pressure gradient and particle rotation (lift force) were all neglected. Particle-particle collisions were neglected. As such, particle motion equations (Yao et al. 2009; Sommerfeld 2003) could be listed as following.

$\frac{\mathrm{d} x_{p i}}{\mathrm{~d} t}=u_{p i}$

$\frac{\mathrm{d} u_{p i}}{\mathrm{~d} t}=F \cdot\left(u_{f i}-u_{p i}\right)\left|u_{f i}-u_{p i}\right|$

$F=\frac{3 C_{\mathrm{D}} \rho_{f}}{4 \rho_{\mathrm{p}} D_{\mathrm{p}}}$

where $f$ was the continuous phase, $p$ was the discrete phase, $x$ was the spatial coordinate position, $t$ was the time, $u$ was the moving velocity, $i$ referred to the spatial orientation. $F$ was the drag force acted on a particle, $D$ was particle diameter, $C_{\mathrm{D}}$ was drag coefficient based on particle Reynolds number $\left(\operatorname{Re}_{\mathrm{p}}\right)$ as shown in Eq. (7), and $\rho$ was particle density.

$$
\begin{array}{rlr}
C_{D} & =\frac{24}{\operatorname{Re}_{\mathrm{p}}}\left(1+0.15 R e_{\mathrm{p}}^{0.6}\right) & \left(\operatorname{Re} e_{\mathrm{p}}<1000\right) \\
& =0.4 & \left(R e_{\mathrm{p}}>1000\right) \\
R e_{\mathrm{p}} & =\frac{D_{\mathrm{p}} \theta\left|u_{f i}-u_{p i}\right|}{v} &
\end{array}
$$

where $v$ was the kinematic viscosity of the continuous phase and $u$ was the time-averaged velocity obtained by RANS.

\subsubsection{Erosion model}

The model used to calculate the erosion was from Zhang et al. (2007) and listed as Eqs. (9) and (10), where particle-wall impact velocity, impact angle, material hardness and particle shape were all considered. These factors were all involved in the erosion occurred in present work.

$$
E_{\mathrm{R}}=C\left(B_{\mathrm{H}}\right)^{-0.59} F_{\mathrm{S}} V_{\mathrm{P}}^{n} F(\theta)
$$

$F(\theta)=\sum_{i=1}^{5} A_{i} \theta^{i}$

where $E_{\mathrm{R}}$ was material erosion rate, $B_{\mathrm{H}}$ was material Brinell hardness and the hardness of 304 stainless steel used in this work was 187. $F_{\mathrm{S}}$ was particle shape coefficient (for example, 1.0 for a sharp particle, 0.53 for a semi-circular particle and 0.2 for a circular particle), $V_{\mathrm{p}}$ was particle-wall impact speed, $\theta$ was impact angle. The values of $C$ and $n$ were obtained empirically as 2.41 and $2.17 \times 10^{-7}$, respectively. $A$ was an empirical constant that was determined by the wall material. The values of $A_{1}$ to $A_{5}$ are shown in Table 2 .

\subsubsection{Wall rebound model}

Particle rebounding characteristics were studied experimentally by Grant and Tabakoff (1975). Particle momentum was modified due to particle-wall impact that was mainly a function of particle impact velocity $V$ and incidence angle $\beta$. The following empirical relationships between rebounding and impacting restitution ratio were used for particle trajectory calculation.

$\frac{V_{n 2}}{V_{n 1}}=1.0-0.4159 \beta_{1}-0.4994 \beta_{1}^{2}+0.292 \beta_{1}^{3}$

$\frac{V_{t 2}}{V_{t 1}}=1.0-2.12 \beta_{1}+3.0775 \beta_{1}^{2}-1.1 \beta_{1}^{3}$

where $V_{\mathrm{n}}$ and $V_{\mathrm{t}}$ represented particle velocity components normal and tangential to wall, respectively. Subscript 1 and 2 referred to before and after particle-wall impact, respectively. In the above equations $\beta_{1}$ (in radians) referred to the angle between incident impact velocity and that tangential to the surface.

\section{Results and discussion}

\subsection{Experimental analysis}

\subsubsection{Particle size}

Silica sands were used in this study and their original shape and size is shown in Fig. 3a, where particle mean size was $0.574 \mathrm{~mm}$. After transported in the loop (Fig. 1) and impacted on the tested specimen, particles were broken and smaller. The morphology of particles working after $42 \mathrm{~h}$ is shown

Table 2 The values of $A_{i}$ in Eq. (10)

\begin{tabular}{lllll}
\hline$A_{1}$ & $A_{2}$ & $A_{3}$ & $A_{4}$ & $A_{5}$ \\
\hline 5.40 & -10.11 & 10.93 & -6.33 & 1.42 \\
\hline
\end{tabular}



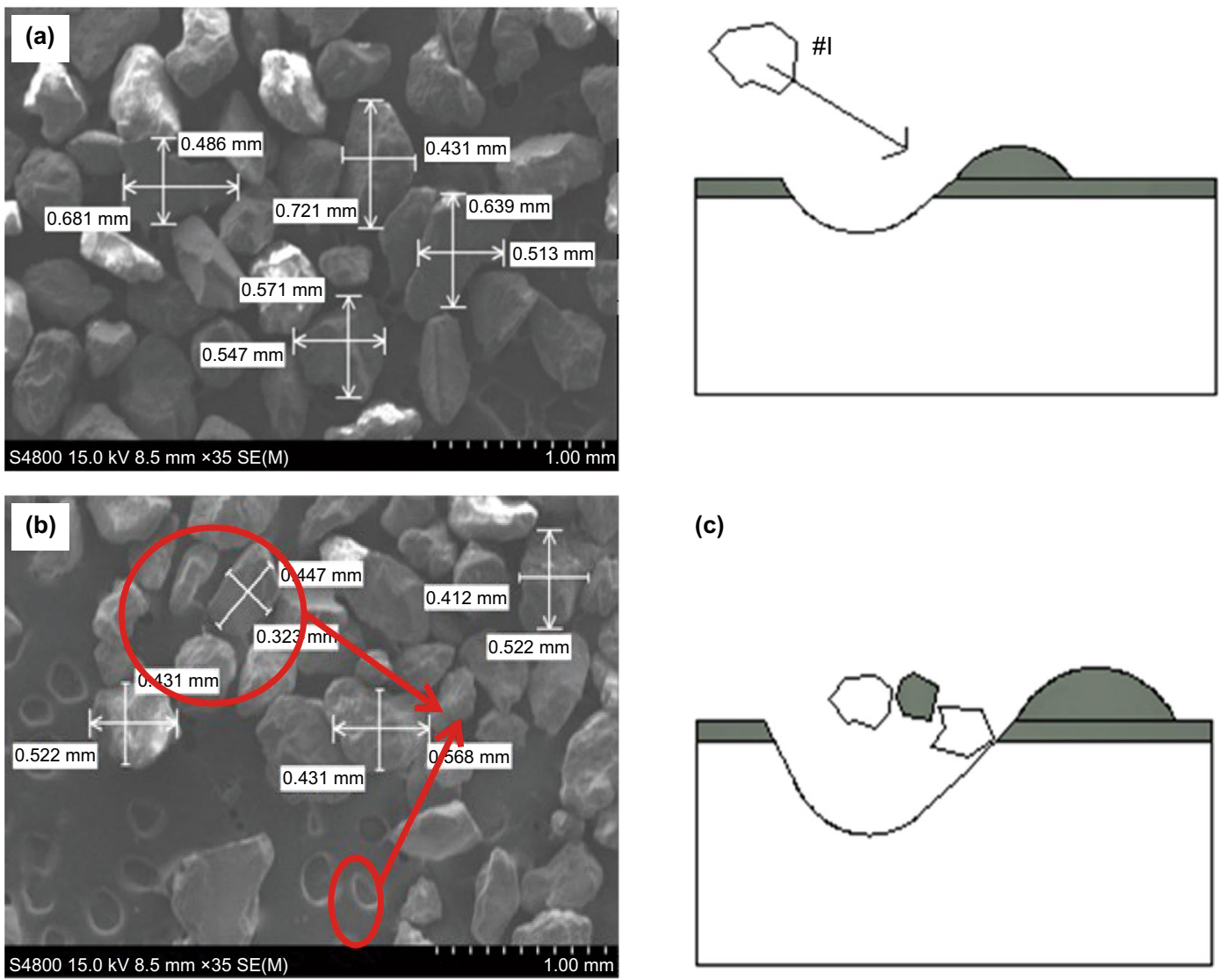

(c)

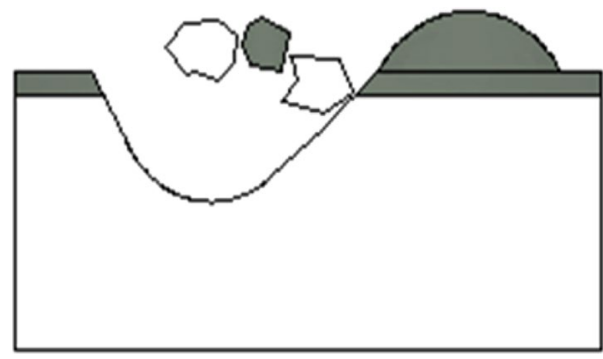

Fig. 3 Morphology of silica sand samples: a original sand particles, b silica sand particles after impinging $42 \mathrm{~h}$; $\mathbf{c}$ sketch of particle breakage

Table 3 Particle size distribution

\begin{tabular}{lllll}
\hline $\begin{array}{l}\text { Erosion } \\
\text { time, hour }\end{array}$ & $0.6-0.7, \mathrm{~mm}$ & $0.5-0.6, \mathrm{~mm}$ & $0.4-0.5, \mathrm{~mm}$ & $<0.4, \mathrm{~mm}$ \\
\hline 0 & $100 \%$ & 0 & 0 & 0 \\
12 & $36.3 \%$ & $45.8 \%$ & $10.9 \%$ & $7 \%$ \\
42 & $25.6 \%$ & $29.8 \%$ & $32.5 \%$ & $12.1 \%$ \\
\hline
\end{tabular}

in Fig. 3b, where particle mean size was $0.457 \mathrm{~mm}$. It was clear that particles became obviously smaller. In addition, another difference between the original particle (Fig. 3a) and the particle working after $42 \mathrm{~h}$ (Fig. 3b) was the shape. To quantitatively evaluate such difference (Yao et al. 2014), "length-ratio" was proposed to describe particle shape as its length divided by its width, where the "length" referred to the maximum length of a particle and the "width" referred to the minimum length of a particle. For example, in Fig. 3a, b, the mean length-ratio was 1.378 and 1.293 , respectively, which showed that particle length-ratio decreased with time. It indicated that particle tended to become round after impacting on metal specimen after $42 \mathrm{~h}$. Therefore, it could be concluded that particles tended to break along the "long" direction. The working mechanism of particle breakage is shown in Fig. 3c. The detail of particle size distribution at 12th hour and 42th hour is shown in Table 3. All original particle size distributed in $0.6-0.7 \mathrm{~mm}$. After $12 \mathrm{~h}$ work, most particles $(82.1 \%)$ distributed in $0.5-0.7 \mathrm{~mm}$. After $42 \mathrm{~h}$ working, more smaller particles were generated, for example, $55.4 \%$ of particles distributed in $0.5-0.7 \mathrm{~mm}, 32.5 \%$ of them distributed in $0.4-0.5 \mathrm{~mm}$ and $12.1 \%$ of them was smaller than $0.4 \mathrm{~mm}$. Hence, it was clear that after long time work particles tended to distribute in smaller size range. The particle distribution in the progress of $42 \mathrm{~h}$ working is shown in Fig. 4.

In this work, after long time ( $39 \mathrm{~h})$ particle-wall impact, most particle size distributed in $0.4-0.5 \mathrm{~mm}$. The weightloss of AISI $304 \mathrm{SS}$ specimen per $3 \mathrm{~h}$ in total $48 \mathrm{~h}$ was measured as shown in Fig. 5. It was found that the weightloss of the AISI 304 SS sample decreased with time and reached the constant level at 39th hour, which met well with the micro-cutting theory proposed by Bitter (1963). This could be explained by the following facts. First, with impact time increased, particle size reduced and each particle mass decreased. In this experiment, $V$ and $p$ were constant [see Eqs. (13)-(14)] from Bitter (1963), with the impact time increased, the total weight-loss of AISI 304 SS 


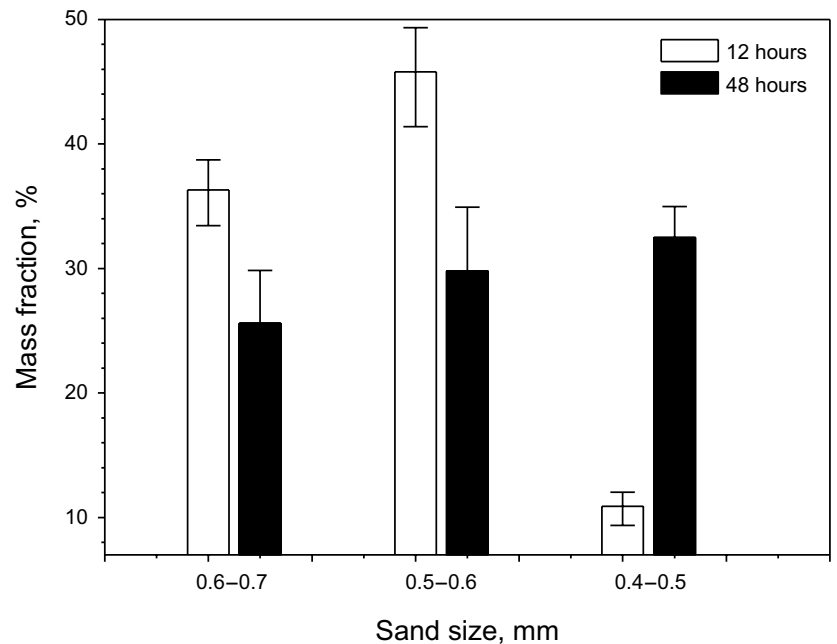

Fig. 4 Silica sand size distribution at different working hours

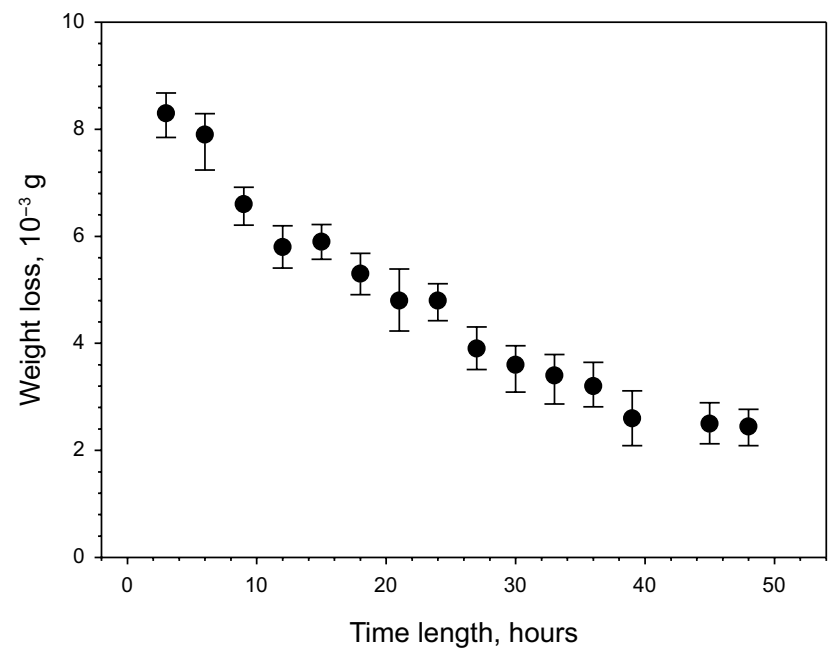

Fig. 5 Total weight-loss of AISI 304 SS (by 0.5\% silica sand) specimens decreased until reached the constant state. Equations (13)-(14) were list as following.

$\mathrm{EV}=k \frac{m V^{2}}{p} f(a)$

$$
\begin{gathered}
f(\alpha)=\sin 2 \alpha-3 \sin ^{2} \alpha \quad\left(\alpha \leq 18.5^{\circ}\right) \\
\cos ^{2} \alpha / 3.0 \quad\left(\alpha>18.5^{\circ}\right)
\end{gathered}
$$

where $m$ was the particle mass; $V$ was the particle velocity; EV was the volume loss of target materials; $p$ was the flow stress and $k$ was the constant (Bitter 1963). Second, as particle diameter decreased to $0.4-0.5 \mathrm{~mm}$, the mass of each particle decreased. Based on the second Newton law as $F=m \cdot a$ that was used to calculate forces acted on a particle, assuming that the acceleration $a$ was constant, force $F$ was proportional to particle mass $m$, for example $F$ decreased with $m$ decreasing. As a particle impacted on wall, the forces acting on the particle had gravity and the counterforce from the wall. It was known that particle gravity was constant so that the force $F$ acted on a particle most related to the counterforce acted from the wall, i.e., $F$ decreased and counterforce decreased. The counterforce acted on a particle was equal to the impacting force acted on wall from the particle. Therefore, it could be deduced that the impacting force (as the counterforce acted on a particle) acted on wall decreased with particle size decreasing. It was seen that in the progress of impinging, particle size became smaller and constant. In this work, after certain period of time ( $39 \mathrm{~h})$, most particle size of silica sands became constant in $0.4-0.5 \mathrm{~mm}$.

\subsubsection{Particle-wall impact region}

In Gnanavelu work (2010), three wear regions due to particle-wall impact were found on the sample surface using Computational Fluid Dynamics (CFD) method, where the impinging angle was set at $90^{\circ}$. In this work, three wear regions were found (as shown in Fig. 6a), which was similar with above work (Gnanavelu 2010) and the
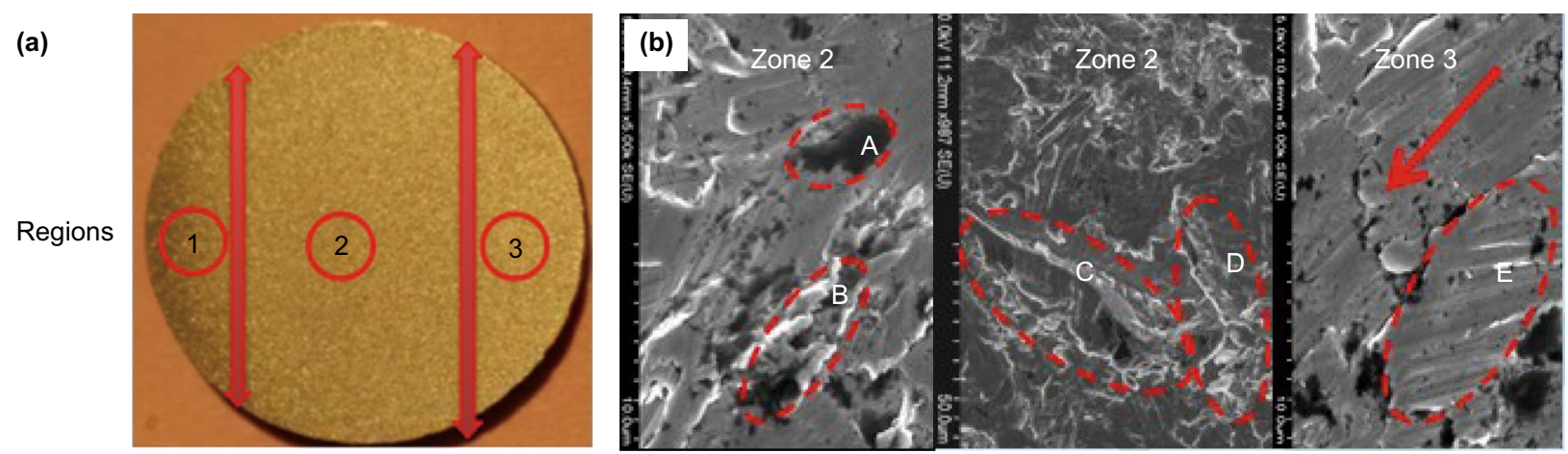

Fig. 6 a Surface wear zones of the specimen from visual inspection; b SEM images of the specimens at different zones 
simulation (Jafar et al. 2015). However, unlike $90^{\circ}$ impinging jet (Gnanavelu 2010), present work of $30^{\circ}$ impinging jet had three unsymmetric wear regions that could nominated as stagnation region (zone 1), cutting transition region (zone 2) and wall jet region (zone 3). The stagnation region (zone 1) had little particle-wall impact due to flow decelerating effect. The transition region (zone 2) had particle-wall impact most occurred at $15^{\circ}-30^{\circ}$ with the same direction as the flow. In the wall jet region (zone 3 ), most particle-wall impact occurred at $15^{\circ}$ or less. In this work, due to impinging set at $30^{\circ}$, most particle-wall impact occurred in the cutting transition region (zone 2) and the wall jet region (zone 3 ). In zone 2, under the flow impinging, the normal force appeared so high that caused surface pits and the tangential force acted on pits to cause weight loss. Such surface pits are shown in Fig. 6b, where the morphology predicted flow path and particles trajectories. It was seen (Fig. 6b) that the number of pits was few where the biggest one was labeled as A, the typical tip was labeled as B and other two big furrows were labeled as $\mathrm{C}$ and $\mathrm{D}$, respectively. In the wall jet region (zone 3), most particles impacted on the wall at angles less than $30^{\circ}$ and the normal force generated was too low to cause erosion to samples. In addition, due to most particle-wall
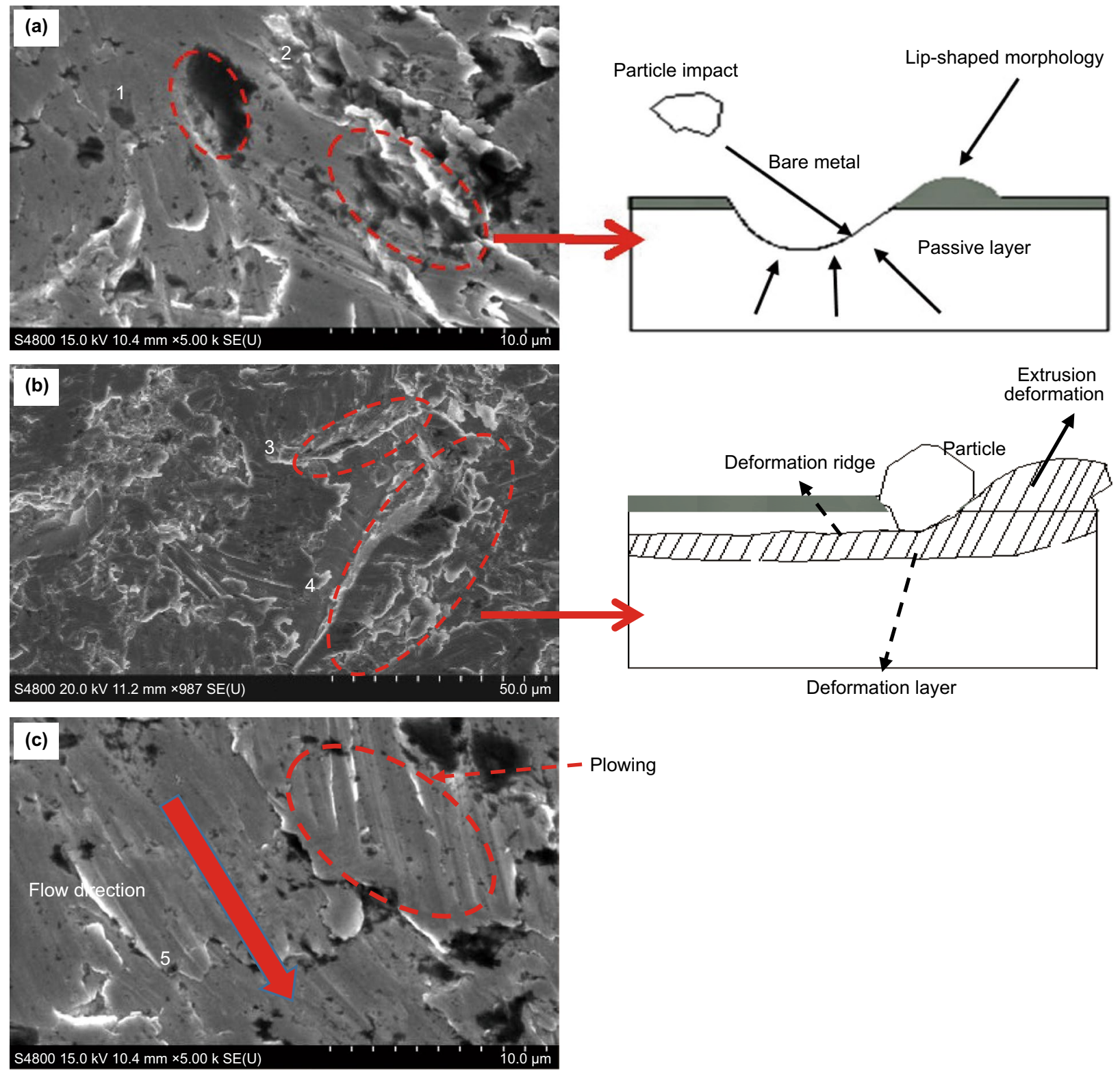

Fig. 7 Morphology of the specimen after impact a cutting transition region (region 2) with presence of hole and lip-shaped hogback; $\mathbf{b}$ wall jet region (region 3) with presence of furrow; $\mathbf{c}$ wall jet region (region 3) with presence of indentation 
impact occurred at low angle, furrows were generated on the sample surface as shown in Fig. 6 b.

Morphologies of the typical cutting transition region (zone 2) are shown in Fig. 7a. It was seen that position 1 had a hole that appeared deep and irregular and position 2 had a lip-shaped hogback that might be caused by shear stress. The lip-shaped hogbacks were found to distribute around the particle-wall impact point and possibly arose from the indentation. The working mechanism could be explained in the next section. In the transition region (zone 2), normal force of particle-wall impact was so strong that generated pits on the surface. As particles impacted on these pits, due to irregular and uneven surface, the impacting and rebounding angles would quite different from the original one and particles deviated from the flow path. These particles were not able to follow with the flow and tended to deposit and accumulate around the pits. With time increased, more and more particles accumulated around pits as shown in Fig. 7a. On the other hand, most particles followed with the impinging jet flow and impacted on the sample surface at the same direction. Afterward, the holes and lip-shaped hogbacks developed in the flow direction.

Morphologies of the typical wall jet region (zone 3) are shown in Fig. 7b, where a groove (position 3 ) and a furrow (position 4) could be found. As analyzed above, in the wall jet region (zone 3), most particle-wall impacting occurred at low angles and the normal force arisen from it was low but the shear stress was high. Under the effect of shear stress, grooves were generated. As particle-wall impaction occurred at grooves and particles subsequently slid along the surface, furrows tended to be generated. In addition, another typical wall jet region (zone 3 ) with particle-wall impact angle less than $15^{\circ}$ is shown in Fig. 7c. Due to particle-wall impact angle being such low, particles tended to slide along the surface and cause shallow indentations with the same direction as the flow path.

The transition region (zone 2) is shown in Fig. 8a, where a long furrow could be found and noted as "d" and another hole noted as "e". Three-dimensional morphology of the "e" hole is shown in Fig. 8b using 3D laser scanning microscopy systems (LSV). The "hole" corner was noted as 1, 2, 3, 4. The heights of each corner were measured, for example, the height at the corner 4 was $8 \mu \mathrm{m}$. Based on each measurement at four corners, the sequence from high to low was $1>2>3>4$, which could be explained by the following facts. As analyzed above, particle-wall impact occurred in the transition region (zone 2) most at $15^{\circ}-30^{\circ}$ and the shear stress generated acted on the corner and determined its height. It could be concluded that the shear stress direction was the same as the flow direction, which caused the height increasing at the same direction as the flow. It agreed well with that obtained by Jafar et al. (2015).

\subsubsection{Particle-wall impact frequency}

In this work, particle-wall impact most occurred in cutting transition region (zone 2) and wall jet region (zone 3). As analyzed above, in the wall jet region (zone 3), particle-wall impact tended to occur at a low angle and the normal force generated was low but the shear stress was so high that created grooves. The averaged depth of the grooves was measured by a 3D laser scanning microscopy system (LSV). The relationship between the averaged groove-depth and the impinging time is shown in Fig. 9a. It was clear that the averaged groove-depth increased with impinging time while the increasing rate decreased with time. It indicated that the averaged groove-depth tended to become constant with the progress of impinging and reach the erosion-steady state in the end.
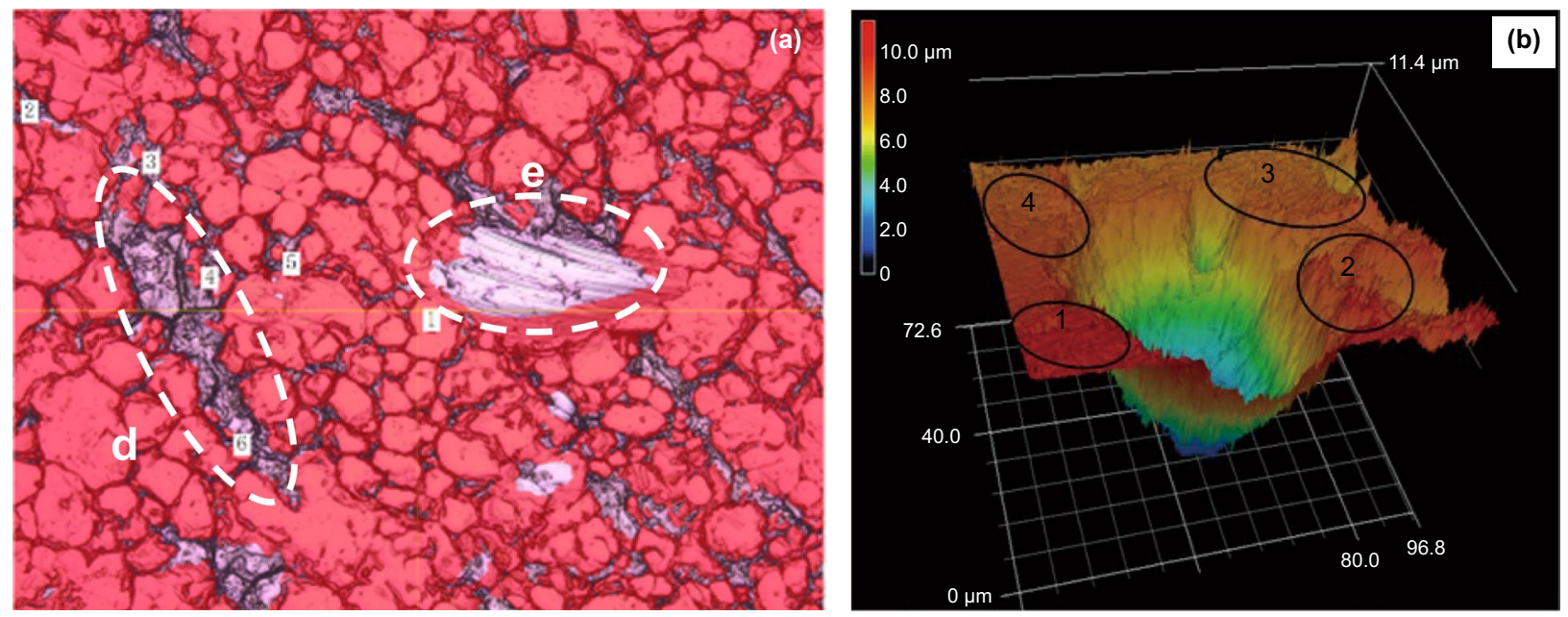

Fig. 8 a Top view of the cutting transition region (zone 2); b 3-dimensional morphology of the hole located at position "e" in a 

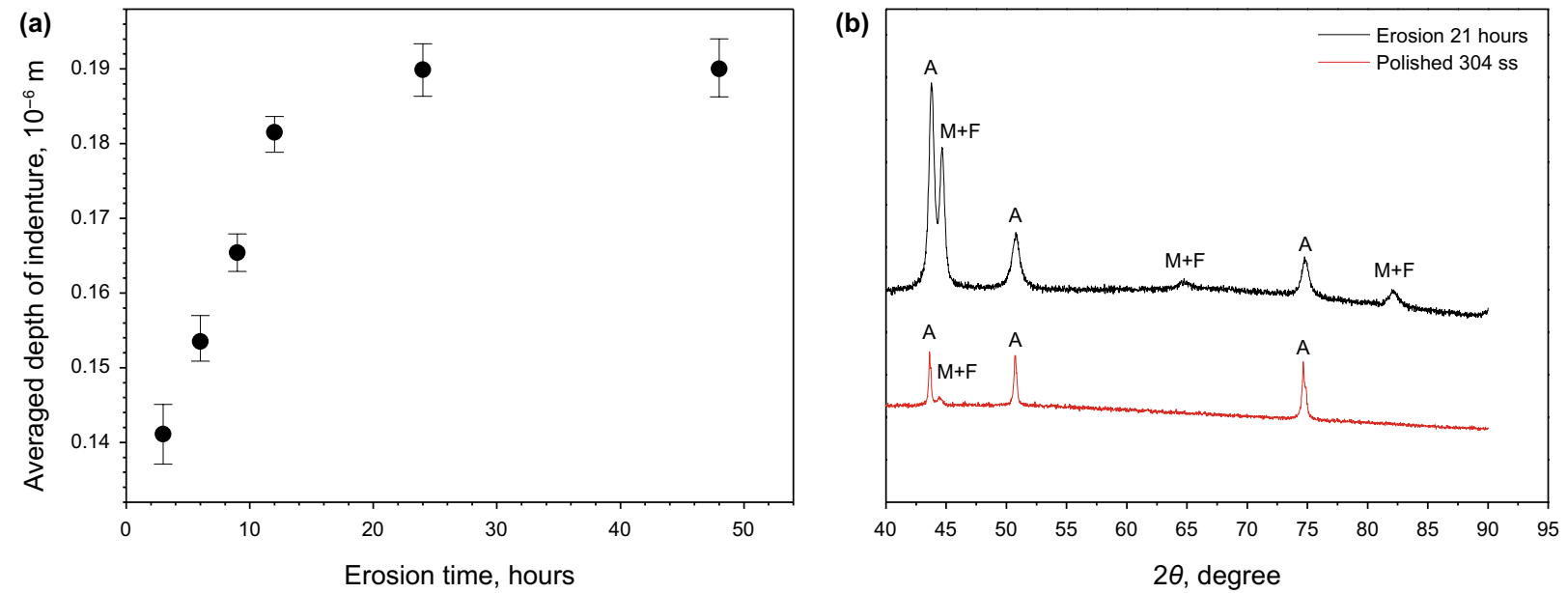

Fig. 9 a The relationship between averaged grooves depth and working time; b XRD pattern of polished AISI 304 SS and that after liquid impinging $21 \mathrm{~h}$

\subsection{Simulation analysis}

Table 4 Simulation conditions

\begin{tabular}{ll}
\hline Particle size (mean size) & $0.574 \mathrm{~mm}$ \\
Particle concentration (by mass) & $0.5 \%$ \\
Impinging jet flow velocity & $10.5 \mathrm{~m} \mathrm{~s}^{-1}$ \\
Particle density (silica sand) & $2650 \mathrm{~kg} \mathrm{~m}^{-3}$ \\
Flow density & $1000 \mathrm{~kg} \mathrm{~m}^{-3}$ \\
Temperature & $45^{\circ} \mathrm{C}$ \\
Impinging angle & $30^{\circ}$ \\
\hline
\end{tabular}

\subsubsection{Particle-wall impact}

XRD spectra for the polished and eroded AISI 304 SS are shown in Fig. 9b. It was seen that the sample contained small amount of ferrite peaks (F) before the test because austenite phase was not $100 \%$. After jet impinging at $10.5 \mathrm{~m} \mathrm{~s}^{-1}$ for $21 \mathrm{~h}$, the XRD pattern of AISI 304 SS sample (Fig. 9b) transformed part of austenite (A) into martensite (M). After work-hardening austenite volume fraction reduced due to higher strain rate sensitivity of austenite as compared to martensite (Liu et al.2003). Therefore, it was clear that particles impacted on the sample to cause strain during mechanical grinding and polishing and transformed part of austenite volume fraction into martensite. Due to structure similarity, the XRD pattern of martensitic peak overlapped austenitic peak. Compared martensitic with austenitic, martensitic erosion resistance was higher than austenitic one. Therefore, the impinging effect increased erosion as well as anti-wear rate. It is one of the reasons why the erosion rate of the sample decreased with time.
In this work, particle tracking was studied using Lagrange method. Particle size, particle concentration, particle impact velocity and other parameters related in the simulation were all set based on the experiment conditions as shown in Table 4. The wear equations used in this simulation were shown by Eqs. (9)-(10). It was assumed that particle shape was circular and particle size was uniform. Due to this flow with mass fraction of particle being $0.5 \%$, particle-particle interaction and particle-flow feedback could be ignored so that single-way coupling of flow and particles was carried out. Figure 10 provides the comparison of simulation results with experimental data. Figure 10a shows the erosion rate in terms of particle mass flow rate for both. It was seen that the simulation results agreed well with the experimental data with a little higher (about 10\%) than the experimental data. The erosion rate increased with particle mass flow rate. Figure $10 \mathrm{~b}$ shows the erosion rate in terms of particle diameter. It was seen that the simulation results agreed with the experimental data with little higher (about 15\%) than the experimental data. The erosion rate increased with particle size. Therefore, it could be concluded that the simulation model and grids used was acceptable by agreement with experimental data.

\subsubsection{Particle tracking analysis}

Particle tracking and its dispersion in the working space are shown in Fig. 11. Most particles trajectories followed the flow route. At the cross region of impinging jet centerline and the tested sample boundary (i.e., high static-pressure region), impinging jet stagnant region could be found. In this region, particle trajectories tended to follow the flow apart 

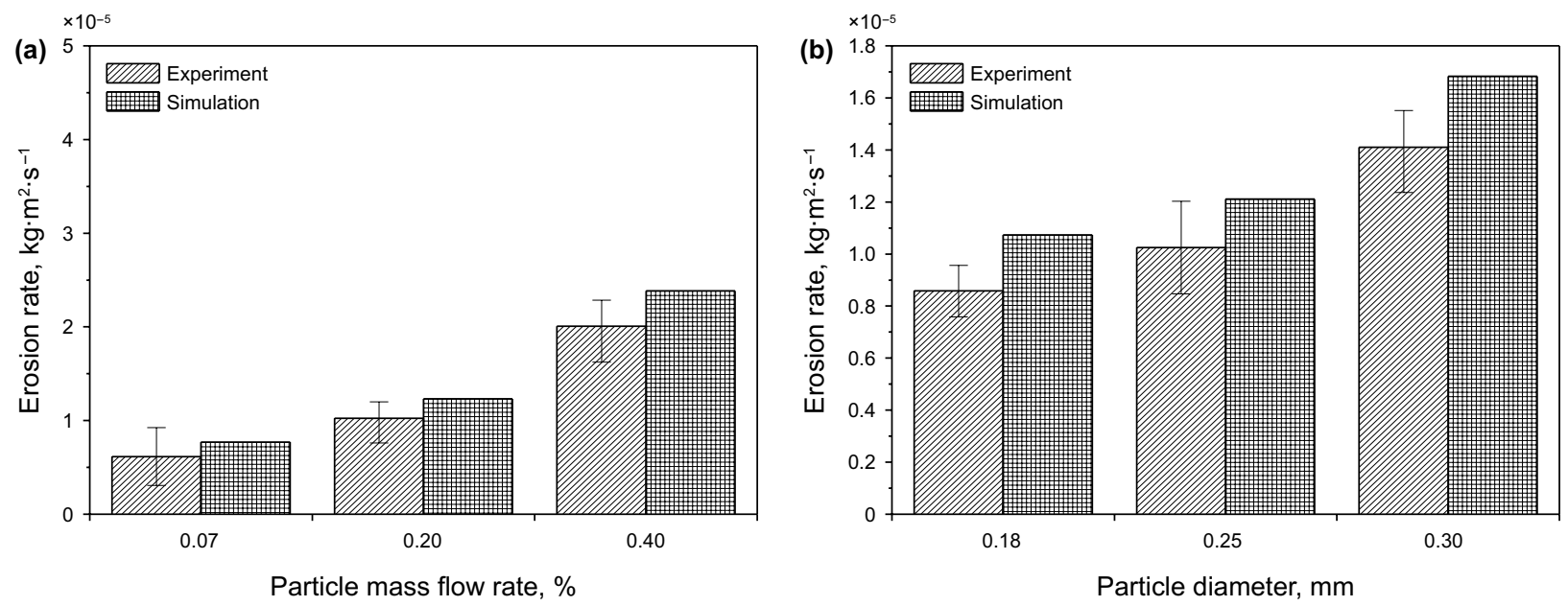

Fig. 10 Comparison of simulation with experimental data. a Erosion rate versus particle mass flow rate; $\mathbf{b}$ erosion rate versus particle diameter

from the core region. The center of the impinging jet corresponded to the sample center so most particles tended to impact on the sample at the core region. The number of particles that directly went against the flow decreased but apart from the flow increased. Whether a particle impacted on the wall or not depended on the flow. Based on the distribution of particle-wall impact simulated, such impacting region could be divided into three parts as defined in Fig. 6a. The detail is shown in Fig. 11a, stagnant region (1) with impact angle larger than $30^{\circ}$, transition region (2) with impact angle $15^{\circ}-30^{\circ}$, wall jet region (3) with impact angle less than $15^{\circ}$. Based on particle trajectory simulated, it was clear that few particle-wall impacting occurred in region 1 due to most particle against the flow direction. In region 2, most particles followed the flow and impacted on the plate at $15^{\circ}-30^{\circ}$ and little of them impacted on the wall at less $15^{\circ}$ in region 3. Overview of such three regions, particle-wall impacting occurred in region 2 might generate high strength at normal direction and caused serious piercing effect at surface as well as cutting process with a lot of material shedding and wearing. On the contrary, in region 3 the normal strength of particle-wall impact was so low that particles hardly penetrated into sample surface resulting in little cutting and wearing. It was clear that the simulation results agreed well with the experimental data as described in above section.

\subsubsection{Particle-wall impact analysis}

It was known that impinging jet flow most dominated particle tracking including particle-wall impact angle and its distribution, which determined the erosion occurred. In this work, erosion state could be characterized by its morphology through eyes or SEM (Scanning Electron Microscopy). As analyzed above, based on erosion difference, particle-wall impacting region could be divided into three parts, which could be further analyzed by particle-wall impact distribution upon simulation results (Fig. 11b, c). In Fig. 11b, particle-wall impact points distributed in a circle with $15 \mathrm{~mm}$ diameter. Based on particle-wall impact calculated (Fig. 11c), three regions could be accurately divided as region 1 from -7.5 to $-4.5 \mathrm{~mm}$, region 2 from -4.5 to $3.5 \mathrm{~mm}$ and region 3 from 3.5 to $7.5 \mathrm{~mm}$. The highest particle-wall impact was found to occur at the sample center $2.5 \mathrm{~mm}$ downstream (shown in Fig. 11c). It was calculated that few points were distributed in region 1 , most points in region 2 and some in region 3. Such particle-wall impact points distribution agreed with the experimental observation as shown in Fig. 6. Again, it confirmed that most particle-wall impact occurred in region 2 leading to heavy erosion. Few particle-wall impacts were found in region 1 because the upstream impinging stagnant area had high static pressure and fairly low flow velocity and push particles apart from the flows.

\subsubsection{Erosion analysis}

Figure 12a shows a particle trajectory impacting on the wall indicating the working mechanism of erosion. The angle between impinging flow and wall was set at $30^{\circ}$. Due to turbulence effect, the flow tended to expand at the impinging direction. In addition, particles were most dominated by the flow and each of them showed various behavior as it impacted on the wall. For example, in Fig. 12a, it was seen that particle 1 went away from the wall without any particle-wall impact and particle 2 impacted on the wall at an angle larger than $30^{\circ}$ while particles 3 and 4 impacting at less than $30^{\circ}$. It could be found that particles 3 and 4 impacted on wall at the angle from $15^{\circ}$ to $30^{\circ}$ that occurred in region 2 , where erosion was the highest. 
(a)
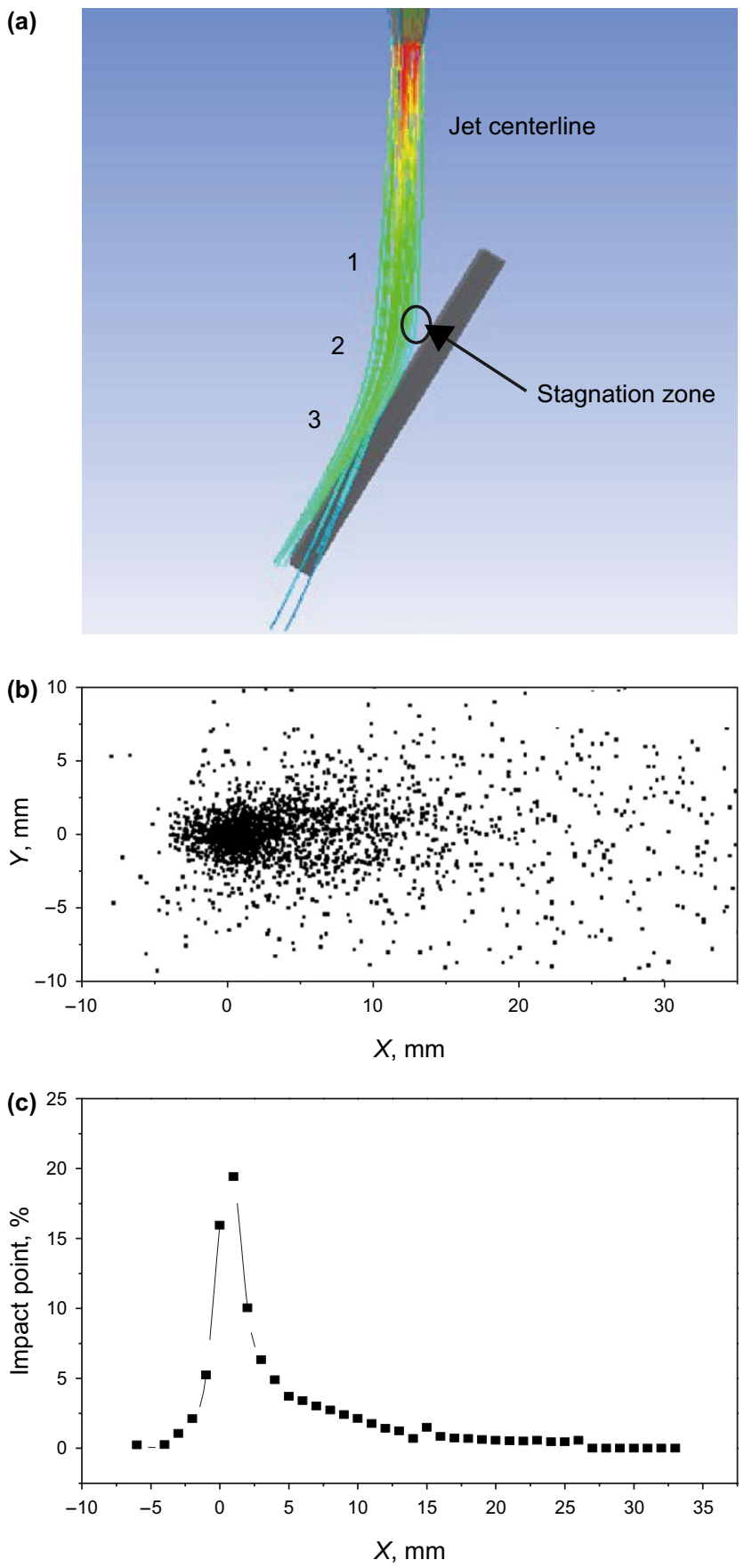

Fig. 11 a Simulation of particle trajectories, $\mathbf{b}$ distribution of particle-wall collision points within three distinctive regions of erosion, c particle-wall impact points distribution by numerical simulation

Figure $12 \mathrm{~b}$ shows the erosion contour of the sample based on simulation. As analysis above, it was known that particle-wall impact region could be divided into three parts. In Fig. 12b, region 1 was from (the edge) $0 \mathrm{~mm}$ to $3 \mathrm{~mm}$ where few particles impacting could be found. Region 2 was from 3 to $11 \mathrm{~mm}$ where most of particle-wall impacting could be found and the corresponding impact angle was from $15^{\circ}$ to $30^{\circ}$. In addition, typical erosion found in region 2 included furrowing, pitting and crumbling. Region 3 was from 11 to $15 \mathrm{~mm}$ where small number of particle-wall impact occurred and the corresponding impact angle was less than $15^{\circ}$. The erosion occurred in region 3 was most due to impression. The simulation of erosion agreed well with the experimental observation above.

\section{Conclusions}

In this work, solid-liquid impinging jet impacting on AISI 304 SS sample was studied both experimentally and numerically. Particle breakage was found and sample erosion were studied. The erosion distribution and related working mechanism was analyzed. Simulation results agreed well with experimental observation. Several conclusions could be summarized as following.

First, for a particle, it might break as particle-wall impacted and its size and shape varied with time. It was found that after $42 \mathrm{~h}$ impacting particles become round. As such, particles tended to break along the "long" direction and finally become round. Regarding the tested specimen, it was found that its weight-loss decreased with time and approached constant after $39 \mathrm{~h}$ working.

Second, the impinging jet set at $30^{\circ}$ had three unsymmetric wear regions that could be nominated as stagnation region (zone 1), cutting transition region (zone 2) and wall jet region (zone 3 ). These regions were identified by experiment and numerical simulation, respectively. Stagnation region (zone 1) had little occurrence of particle-wall impact while cutting transition region (zone 2) had much occurrence most at the angle of $15^{\circ}-30^{\circ}$. Wall jet region (zone 3 ) had small amount of particle-wall impact at the angle less than $15^{\circ}$. In this work, due to impinging jet set at $30^{\circ}$ with the sample impacted, most particle-wall impact occurred in cutting transition region (zone 2) and wall jet region (zone 3 ).

Third, in cutting transition region (zone 2), under flow impinging, normal force appeared high to induce surface pits and tangential force affected pits to increase weight loss. Lip-shaped hogbacks could be found to distribute around the particle-wall impacting core region that possibly arose from the indentation. Such holes and lip-shaped hogbacks were shaped in the same direction as the flow path. In wall jet region (zone 3), most particles impacted on the wall at angles less than $30^{\circ}$ so the normal force generated was low but the shear stress generated was fairly high. Furrows and grooves were found popularly on the sample surface. In this region, particles tended to slide along surface and cause shallow indentations with the same direction as the flow. It was found that the averaged grooves depth increased with 

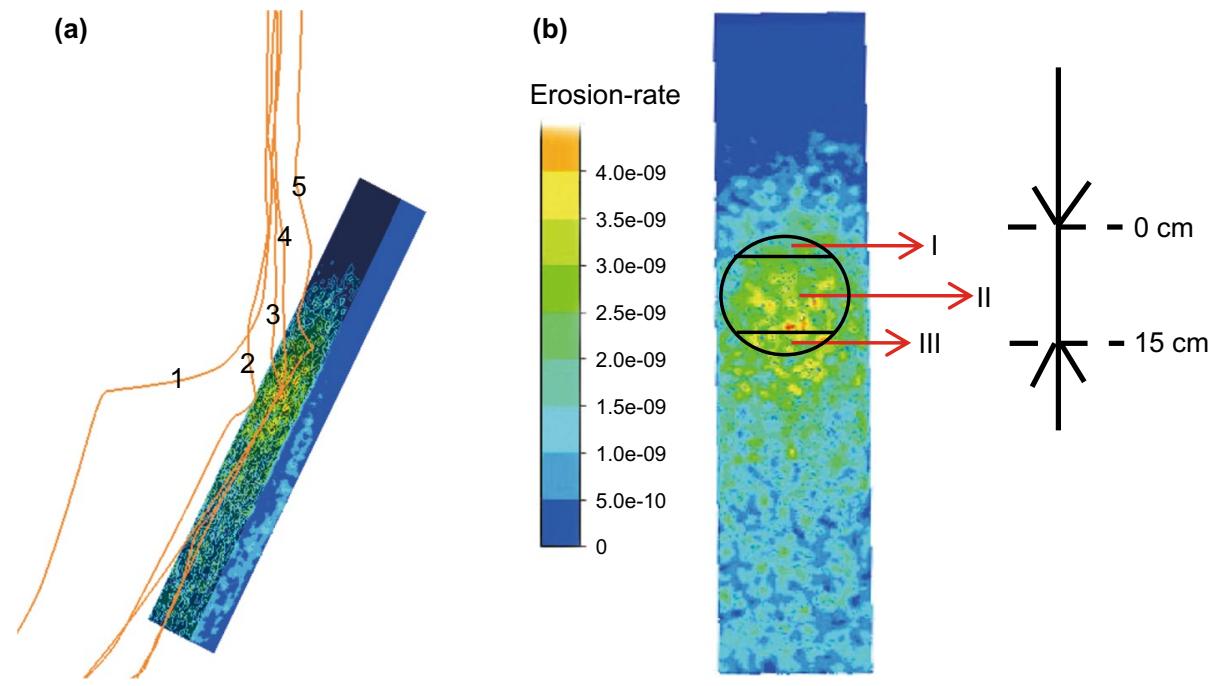

Fig. 12 a The trajectory of single particle impact with wall; $\mathbf{b}$ the erosion contour of the sample surface (erosion rate: $0-4 \mathrm{E}^{-09}, 50$ contour levels are given and scaled linearly between the minimum and maximum level)

impinging time while the increasing rate decreased with time. It was found that the averaged grooves depth tended to become constant with the progress of impinging and approach steady in the end.

Last, in this work using two-phase impinging jet, part of austenite peaks (A) of AISI 304 SS was found to transform into martensite peaks (M). Compared martensite with austenite, martensitic erosion resistance was higher than austenitic erosion resistance. Therefore, the impinging effect increased the sample erosion as well as improved its antiwear rate.

Acknowledgements This work was supported by National Natural Science Foundation of China (Nos. 51776225; 51876221) and High-end Foreign Expert Introduction Project (G20190001270; B18054).

Open Access This article is licensed under a Creative Commons Attribution 4.0 International License, which permits use, sharing, adaptation, distribution and reproduction in any medium or format, as long as you give appropriate credit to the original author(s) and the source, provide a link to the Creative Commons licence, and indicate if changes were made. The images or other third party material in this article are included in the article's Creative Commons licence, unless indicated otherwise in a credit line to the material. If material is not included in the article's Creative Commons licence and your intended use is not permitted by statutory regulation or exceeds the permitted use, you will need to obtain permission directly from the copyright holder. To view a copy of this licence, visit http://creativecommons.org/licenses/by/4.0/.

\section{References}

Abedini M, Ghasemi HM. Synergistic erosion-corrosion behavior of Al-brass alloy at various impingement angles. Wear. 2014;319:49-55. https://doi.org/10.1016/j.wear.2014.07.008.
Agrawal M, Khanna S, Kopliku A, Lockett T. Prediction of sand erosion in CFD with dynamically deforming pipe geometry and implementing proper treatment of turbulence dispersion in particle tracking. Wear. 2019;426-427:596-604. https://doi.org/10.1016/j. wear.2019.01.018.

Akama M, Kimata T. Numerical simulation model for the competition between short crack propagation and wear in the wheel tread. Wear. 2020;448-449:203-5. https://doi.org/10.1016/j. wear.2020.203205.

Al-Bukhaiti MA, Ahmed SM, Badran FMF, Emara KM. Effect of impingement angle on slurry erosion behaviour and mechanisms of 1017 steel and high-chromium white cast iron. Wear. 2007;262:1187-98. https://doi.org/10.1016/j.wear.2006.11.018.

Alade OS, Mahmoud M, Al-Shehri D. Investigation into the effect of silica nanoparticles on the rheological characteristics of water-inheavy oil emulsions. Pet Sci. 2019. https://doi.org/10.1007/s1218 2-019-0330-x.

Aribo S, Barker R, Hu X, Neville A. Erosion-corrosion behaviour of lean duplex stainless steel in $3.5 \mathrm{wt} \% \mathrm{NaCl}$ solution. Wear. 2013;302:1602-8. https://doi.org/10.1016/j.wear.2012.12.007.

Ben-Ami Y, Uzi A, Levy A. Modelling the particles impingement angle to produce maximum erosion. Powder Technol. 2016;301:103243. https://doi.org/10.1016/j.powtec.2016.07.041.

Bitter JG. A study of erosion phenomena. Wear. 1963;6:5-21. https:// doi.org/10.1016/0043-1648(63)90003-6.

Burstein GT, Sasaki K. Effect of impact angle on the slurry erosioncorrosion of 304L stainless steel. Wear. 2000;240:80-94. https:// doi.org/10.1016/S0043-1648(00)00344-6.

Fan JR, Yao J, Zhang X, Cen K. Experimental and numerical investigation of a new method for protecting bends from erosion in gasparticle flows. Wear. 2001;251:853-60. https://doi.org/10.1016/ S0043-1648(01)00742-6.

Finnie I, Stevick GR, Ridgely JR. The influence of impingement angle on the erosion of ductile metals by angular abrasive particles. Wear. 1992;152:91-8. https://doi.org/10.1016/00431648(92)90206-N.

Finnie I. Erosion of surfaces by solid particles. Wear. 1960;3:87. https ://doi.org/10.1016/0043-1648(60)90055-7.

Grant G, Tabakoff W. Erosion prediction in turbomachinery resulting from environmental solid particles. J Aircraft. 1975;12:471-506. https://doi.org/10.2514/3.59826. 
Gnanavelu A. A geometry independent integrated method to predict erosion wear rates in a slurry environment. Ph.D. Thesis, School of Mechanical Engineering, University of Leeds; 2010. http:// etheses.whiterose.ac.uk/id/eprint/4398.

Han HX, Yin S, Aadnoy BS. Impact of elliptical boreholes on in situ stress estimation from leak-off test data. Pet Sci. 2018;15(04):11622. https://doi.org/10.1007/s12182-018-0248-8.

Jin T, Luo K, Fan JR, Yang JS. Immersed boundary method for simulations of erosion on staggered tube bank by coal ash particles. Powder Technol. 2012;225:196-205. https://doi.org/10.1016/j. powtec.2012.04.008.

Jafar RHM, Nouraei H, Emamifar M, Papini M, Spelt JK. Erosion modeling in abrasive slurry jet micro-machining of brittle materials. J Manuf Process. 2015;17:127-40. https://doi.org/10.1016/j. jmapro.2014.08.006.

Khayatan N, Ghasemi HM, Abedini M. Synergistic erosion-corrosion behavior of commercially pure titanium at various impingement angles. Wear. 2017;380-381:154-62. https://doi.org/10.1016/j. wear.2017.03.016.

Luo K, Wang ZL, Fan JR. A modified immersed boundary method for simulations of fluid-particle interactions. Comput Methods Appl Mech Eng. 2007;197:36-46. https://doi.org/10.1016/j. cma.2007.07.001.

Lopez D, Sanchez C, Toro A. Corrosion-erosion behavior of TiNcoated stainless steels in aqueous slurries. Wear. 2005;258:68492. https://doi.org/10.1016/j.wear.2004.09.015.

Levy AV. The erosion of structure alloys, ceramets and in situ oxide scales on steels. Wear. 1988;127:31-52. https://doi. org/10.1016/0043-1648(88)90051-8.

Liu W, Zheng YG, Liu CS, Yao ZM, Ke W. Cavitation erosion behaviour of $\mathrm{Cr}-\mathrm{Mn}-\mathrm{N}$ stainless steels in comparison with $0 \mathrm{Cr} 13 \mathrm{~N}$ i5Mo stainless steel. Wear. 2003;254:713-22. https://doi. org/10.1016/S0043-1648(03)00128-5.

Mohammadi F, Luo J. Effect of particle angular velocity and friction force on erosion enhanced corrosion of 304 stainless steel. Corros Sci. 2010;52:2994-3001. https://doi.org/10.1016/j.corsc i.2010.05.012.

Nguyen QB, Lim CYH, Nguyen VB, Wan YM, Nai B, Zhang YW, et al. Slurry erosion characteristics and erosion mechanisms of stainless steel. Tribol Int. 2014a. https://doi.org/10.1016/j.tribo int.2014.05.014.

Nguyen QB, Nguyen VB, Lim CYH, Trinh QT, Sankaranaraynan S, Zhang YW, et al. Effect of impact angle and testing time on erosion of stainless steel at higher velocities. Wear. 2014b;321:87-93. https://doi.org/10.1016/j.wear.2014.10.010.

Pool KV, Dharan CKH, Finnie I. Erosive wear of composite materials. Wear. 1986;107:1-12. https://doi.org/10.1016/00431648(86)90043-8.

Qi H, Wen DH, Yuan QL, Zhang L, Chen ZZ. Numerical investigation on particle impact erosion in ultrasonic-assisted abrasive slurry jet micro-machining of glasses. Powder Technol. 2017;314:627-34. https://doi.org/10.1016/j.powtec.2016.08.057.

Rajahram SS, Harvey TJ, Wood RJK. Electrochemical investigation of erosion-corrosion using a slurry pot erosion tester. Tribol Int. 2011;44:232-40. https://doi.org/10.1016/j.triboint.2010.10.008.

Samimi A, Moreno R, Ghadiri M. Analysis of impact damage of agglomerates: effect of impact angle. Powder Technol. 2004;143:97-109. https://doi.org/10.1016/j.powtec.2004.04.027.

Stack MM, Corlett N, Zhou S. Impact angle effects on the transition boundaries of the aqueous erosion-corrosion map.
Wear. 1999;225-229:190-8. https://doi.org/10.1016/S0043 -1648(99)00050-2.

Sommerfeld M. Analysis of collision effects for turbulent gas-particle flow in a horizontal channel: part I, particle transport. Int J Multiphase Flow. 2003;29:675-99. https://doi.org/10.1016/S0301 -9322(03)00031-4.

Telfer CG, Stack MM, Jana BD. Particle concentration and size effects on the erosion-corrosion of pure metals in aqueous slurries. Tribol Int. 2012;53:35-44. https://doi.org/10.1016/j.tribo int.2012.04.010.

Tilly GP, Sage W. The interaction of particle and material behaviour in erosion processes. Wear. 1970;16:447-65. https://doi. org/10.1016/0043-1648(70)90171-7.

Wellman RG, Allen C. The effects of angle of impact and material properties on the erosion rates of ceramics. Wear. 1995;186:11722. https://doi.org/10.1016/0043-1648(95)07130-X.

Yao J, Li JZ, Zhao YL. Investigation of granule dispersion in turbulent pipe flows with electrostatics. Adv Powder Technol. 2020. https ://doi.org/10.1016/j.apt.2020.01.026.

Yao J, Zhao YL, Li N, Zheng YQ, Hu GL, Fan JR, et al. Mechanism of particle transport in a fully developed wake flow. Ind Eng Chem Res. 2012;51:10936-48.

Yao J, Wu JJ, Zhao YL, Lim EWC, Cao PG, Zhou F, et al. Experimental investigations of granular shape effects on the generation of electrostatic charge. Particuology. 2014;15:82-9. https://doi. org/10.1016/j.partic.2013.01.010.

Yao J, Zhao YL, Hu GL, Fan JR, Cen KF. Numerical simulation of particle dispersion in the wake of a circular cylinder. Aerosol Sci Technol. 2009;43:174-87. https://doi.org/10.1080/0278682080 2549441.

Yao J, Zhou F, Zhao YL, Yin H, Li N. Investigation of erosion of stainless steel by two-phase jet impingement. Appl Therm Eng. 2015;88:353-62. https://doi.org/10.1016/j.applt hermaleng.2014.08.056.

Yi JZ, Hu HX, Wang ZB, Zheng YG. On the critical flow velocity for erosion-corrosion in local eroded regions under liquidsolid jet impingement. Wear. 2019;422-423:94-9. https://doi. org/10.1016/j.wear.2019.01.069.

Yildizli K, Karamiş MB, Nair F. Erosion mechanisms of nodular and gray cast irons at different impact angles. Wear. 2006;261:622-33. https://doi.org/10.1016/j.wear.2006.01.042.

Yin BT, Li XF, Liu GA. Mechanistic model of heat transfer for gasliquid flow in vertical wellbore annuli. Pet Sci. 2018;15:135-45. https://doi.org/10.1007/s12182-017-0193-y.

Zhang GA, Xu LY, Cheng YF. Investigation of erosion-corrosion of 3003 aluminum alloy in ethylene glycol-water solution by impingement jet system. Corros Sci. 2009;51:283-90. https:// doi.org/10.1016/j.corsci.2008.10.026.

Zhao YL, Wang YZ, Yao J, Fairweather M. Reynolds number dependence of particle resuspension in turbulent duct flows. Chem Eng Sci. 2018;187:33-51.

Zhao YL, Zhou F, Yao J, Dong SG, Li N. Erosion-corrosion behavior and corrosion resistance of AISI 316 stainless steel in flow jet impingement. Wear. 2015;328-329:464-74. https://doi. org/10.1016/j.wear.2015.03.017.

Zhang YL, Reuterfors EP, McLaury BS, Shirazi SA, Rybicki EF. Comparison of computed and measured particle velocities and erosion in water and air flows. Wear. 2007;263:330-8. https://doi. org/10.1016/j.wear.2006.12.048. 